\title{
Tribology and Mechanical Properties of Carbon Fabric/MWCNT/Epoxy Composites
}

\author{
B. Shivamurthy $\left(D,{ }^{1}\right.$ Krishna Murthy, ${ }^{1}$ and S. Anandhan ${ }^{2}$ \\ ${ }^{1}$ Department of Mechanical and Manufacturing Engineering, Manipal Institute of Technology, \\ Manipal Academy of Higher Education, Manipal 576 104, Karnataka, India \\ ${ }^{2}$ Department of Metallurgical and Materials Engineering, National Institute of Technology Karnataka, \\ Srinivas Nagar, Mangalore 575025, Karnataka, India
}

Correspondence should be addressed to B. Shivamurthy; shiva.b@manipal.edu

Received 30 January 2018; Revised 8 May 2018; Accepted 13 June 2018; Published 5 July 2018

Academic Editor: Shyam Bahadur

Copyright (C) 2018 B. Shivamurthy et al. This is an open access article distributed under the Creative Commons Attribution License, which permits unrestricted use, distribution, and reproduction in any medium, provided the original work is properly cited.

Cryogenic treated multilayered carbon fabric/oxidized multiwall carbon nanotube/epoxy (CCF/O-MWCNT/E) composite and untreated carbon fabric/epoxy $(\mathrm{CF} / \mathrm{E})$ composite were prepared by hot compression molding technique. The density and mechanical properties such as tensile properties, flexural properties, interlaminar shear strength, and microhardness of the composites were investigated as per ASTM standards. The wear and coefficient of friction behavior were investigated using computer interfaced pin-on-disc test rig at room temperature for varied load and sliding speed. The morphology of worn surfaces of the wear test composite specimens were studied by scanning electron microscope. It is found that the synergetic effect of addition of OMWCNT to epoxy matrix and cryogenic treatment of carbon fabric improved the wear resistance and mechanical properties. Also, a thin lubricating film developed by the oxidized multiwall carbon nanotube/epoxy wear debris reduces the coefficient of sliding friction and wear rate.

\section{Introduction}

Conventional materials are being replaced with carbon fiber reinforced polymer (CFRP) composites in aeronautical industries due to their attractive specific mechanical properties [1]. CFRP composites are also used extensively in automotive, marine, and sports equipment. They possess high strength-to-weight ratio as well as high stiffness-to-weight ratio compared with conventional materials. However, these composites have multilayered construction; the shear strength in between the layers (interlaminate shear property) depends on the matrix used. They have much weaker interlaminar shear strength $\left(\tau_{\text {ils }}\right)$ than tensile strength $\left(\sigma_{\mathrm{t}}\right)$ and bending strength $\left(\sigma_{\mathrm{f}}\right)$. This is one of the limitations in CFRP composites used in aerospace structures [2].

In addition to the above-mentioned mechanical properties, the sliding wear behavior and coefficient of friction at the contact zones (which is due to relative motion between parts) of CFRP composites were also important for better performance. But, the sliding wear behavior of a CFRP composite part depends on both matrix and reinforcement used in addition to operating conditions [3]. It is found from literature that the self-lubricating property of the carbon fiber in CFRP composite improves the wear resistance by reducing the coefficient of friction [3]. Furthermore, to improve the wear resistance and to reduce the coefficient of friction, many researchers used fillers in the form of particulate or flakes in epoxy matrix with carbon fabrics/short fibers/long fibers and nanofibers as reinforcement [4-6]. Due to the application of high performance epoxy polymer as matrix with carbon fiber and filler as reinforcement the resulting hybrid composite exhibits higher mechanical properties and lower specific wear rate with low coefficient of friction compared to unfilled carbon fabric-reinforced epoxy composites. In this context, many researchers reported and found that addition of filler results in improved mechanical and wear resistant properties of CFRP composites.

Kumaresan et al. reported that addition of silicon carbide filler to carbon fabric-reinforced epoxy composites increase the wear resistance and mechanical properties [4]. Cho et al. 
stated addition of nanoparticulate graphite to carbon fiber reinforced epoxy composites enhances the in-plane shear properties and compressive strength of composites [5]. Guo et al. reported that addition of surface modified $\mathrm{SiO}_{2}$ filler decreases the wear loss and coefficient of friction of short carbon fiber reinforced epoxy composite [6]. Research literatures also conclude that the surface treatment of nanoparticles improves matrix property due to good interface [7-9]. Chang and Friedrich reported that the load carrying capacity of the short fiber reinforced composites is determined by the fiber properties and their quality of interface with matrix. They also observed that the wear was improved by addition of nanoparticles [10]. Su et al. demonstrated that addition of nano $\mathrm{Al}_{2} \mathrm{O}_{3}$ and nano- $\mathrm{Si}_{2} \mathrm{~N}_{4}$ in carbon fabric-reinforced epoxy composite improves the friction and wear properties [11]. Hence, it is clear from the literature that addition of judicious amount of ceramic or solid lubricant nanofiller improves the wear resistance by reducing coefficient of friction of the polymer composites [11, 12]. In addition to type, shape, size, and quantity of filler, better manufacturing method of composites and the surface treatment to the reinforcements (fiber or filler or both) before incorporation into composites helps to achieve better interface and enhances both fiber and matrix dominating properties in the composite $[13,14]$.

Out of many types of nanofillers, carbon nanotubes (CNTs) are an attractive nanophase reinforcement material for metal and polymer matrix. The MWCNT was selected as reinforcing filler in many hybrid polymer composite preparations due to its excellent multifunctional and structural properties, nanosize, high aspect ratio, and surface area $[13,14]$.

Based on the above inputs, in this research work authors prepared nanohybrid polymer composites by incorporating surface treated MWCNTs and cryogenically treated carbon fabric as reinforcements in epoxy resin matrix. The mechanical and tribological properties of the composites were investigated and compared with untreated carbon fabric-reinforced epoxy composite.

\section{Materials and Methods}

2.1. Materials. Epoxy resin (LAPOX ARL-135) and hardener (LAPOX AH-335) were supplied by Atul Ltd. Valsad, Gujarat, India, was used as matrix. Bidirectional plain weave type carbon fabric (Material code: HCP 200, area density: 200 g.m ${ }^{-2}$, $\pm 5 \%$, fiber type: $3 \mathrm{k}$, supplier: Hindustan Technical Fabrics Ltd., India) was used as reinforcement. The MWCNTs (Product No: 677248, outer diameter: 10-15 nanometers, inner diameter: 2-6 nanometers, length: 0.1-10 micrometers, purity: $90 \%$, production method: Chemical vapor deposition) supplied by M/s Sigma-Aldrich, Bangalore, India, were used as filler. Potassium dichromate of extra pure quality was obtained from Sulab, Baroda, India, and sulfuric acid from Nice Chemicals, Cochin, India, was used for treatment of MWCNTs.

\subsection{Fabrication of Composites}

2.2.1. Treatment of MWCNT. $0.2 \mathrm{~g}$ of potassium dichromate was dissolved in $5 \mathrm{ml}$ of $10 \mathrm{~N}$ sulfuric acid and $50 \mathrm{mg}$ of
MWCNTs was added to this mixture and kept at $80^{\circ} \mathrm{C}$ in a constant temperature bath for 30 minutes. The mixture was ultrasonicated for 1 hour to remove agglomeration. Then the mixture was centrifuged and washed repeatedly several times until a neutral $\mathrm{pH}$ is attained. The filtered MWCNT was dried in a vacuum oven at $100^{\circ} \mathrm{C}$ before being mixed with the epoxy resin to remove the moisture.

2.2.2. Treatment of Carbon Fabric. Plain-woven carbon fabric was cut into pieces of size $300 \mathrm{~mm} \times 300 \mathrm{~mm}$ from the supplied width of $1000 \mathrm{~mm}$ and placed in acetone bath for about 24 hours to remove the sizing. The fabric was then washed with deionized water and dried at room temperature. After complete cleaning, the fabric was immersed in liquid nitrogen tank at $-195^{\circ} \mathrm{C}$ for about 4 minutes.

2.2.3. Fabrication of Nanocomposite. A measured quantity of O-MWCNT was dispersed in epoxy resin by ultrasonication method. The specific parameters used for this study were: amplitude of $40 \%$ of $20 \mathrm{kHz}$ for the duration of first 5 minutes and later $20 \%$ for the rest 1 hour 55 minutes with a pulse of 5 seconds $\mathrm{ON}$ and 2 seconds OFF.

After the complete dispersion the hardener was mixed to epoxy resin at a v/v ratio of 20:7 using hot plate magnetic mixer at $60^{\circ} \mathrm{C}$ and $1500 \mathrm{rpm}$. The resin mixture was coated on each layer of carbon fabric by a brush and a roller. Twelve such layers were kept between the pressing platens of a hydraulic press. A gel coat was applied on the platen plates for mold release and to obtain smooth composite slabs. Resin impregnated fabric stock was initially pressed with low pressure up to 10 minutes. Further, the hydraulic ( $40 \mathrm{~T}$ capacity) pressure of $0.5 \mathrm{MPa}$ was maintained and pressed for 24 hours at room temperature. The excess resin was squeezed out during pressing. By the above process composite laminates were produced with a fiber volume ratio of $0.55( \pm 3 \%)$ and MWCNTs of 0.035 weight $\%$. Similar steps of procedures were followed to fabricate untreated carbon fabric-reinforced epoxy composite without MWCNTs. The composite slabs of a size of 300 $\mathrm{mm} \times 300 \mathrm{~mm} \times 3 \mathrm{~mm}$ were prepared at room temperature curing followed by the above method and finally postcured for 4 hours at $80^{\circ} \mathrm{C}$ for further more crosslinking of epoxy monomers with monomers of hardener in the composites.

\subsection{Testing and Characterization}

2.3.1. Physical and Mechanical Test. The CF/E composite and CCF/O-MWCNT/E composite were tested as per ASTM standards to estimate the physical and mechanical properties. Actual density of the composites was measured according to ASTM: D 792-10 [15]. Vickers hardness (VH) of the composite specimens was measured by using a Matsuzawa microhardness testing machine (Model No. MMT-X7A, Japan). Tensile behavior was investigated as per ASTM: D 638-10 [16]; three-point bending technique was adopted to investigate flexural properties of the composites as per ASTM: D 79010 [17]; interlaminar shear strength $\left(\tau_{\mathrm{ils}}\right)$ was investigated according to ASTM: D 2344-76 [18] using universal testing machine (Instron 3366). In each case to evaluate the physical 


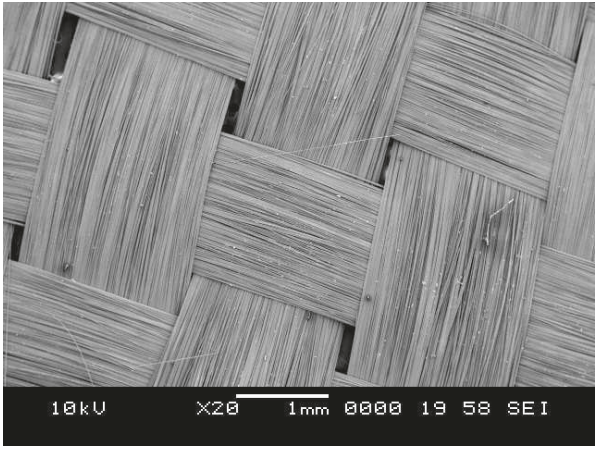

(a)

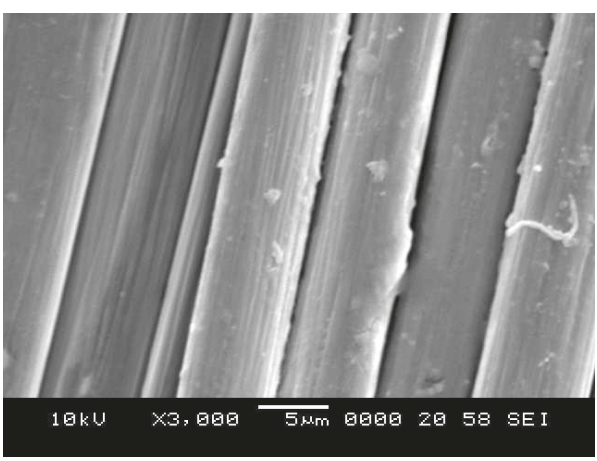

(c)

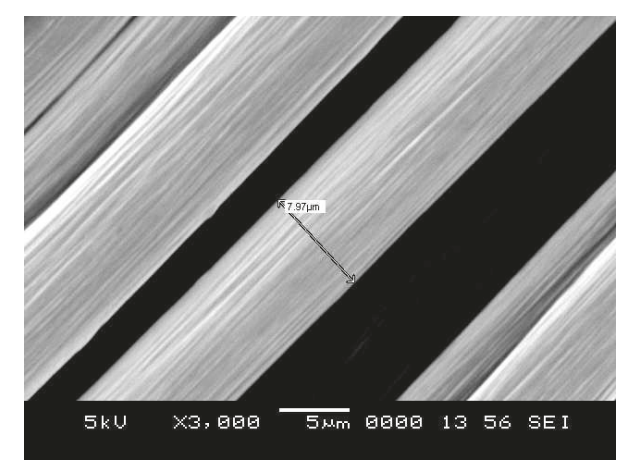

(b)

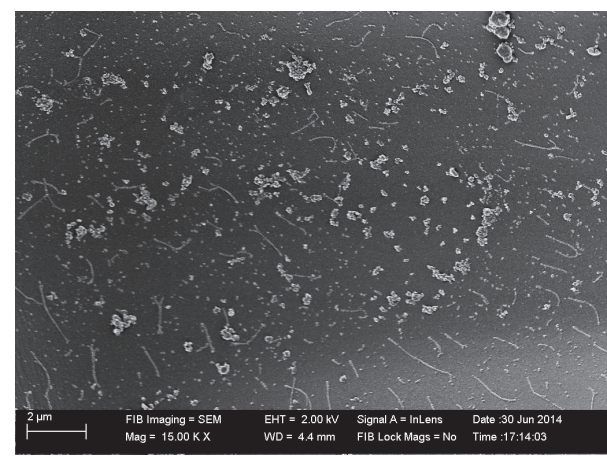

(d)

FIGURE 1: SEM images of (a) carbon fabric, (b) carbon fibers in carbon fabric as-received from the supplier, (c) cryogenically treated carbon fibers, and (d) FESEM image of MWCNTs dispersion in epoxy matrix.

and mechanical properties five samples were tested and found that a variation of $3 \%$. The average test results are reported.

2.3.2. Sliding Wear Test. The cured composite laminates were cut by using a diamond tipped cutter to obtain wear test coupons of $5 \mathrm{~mm}$ square. Four such samples were then glued using an adhesive to make pins of size $5 \mathrm{~mm}$ square shape and $12 \mathrm{~mm}$ length. Sliding wear test was carried out at sliding velocities of $1.5,2.5$, and $3.5 \mathrm{~m} . \mathrm{s}^{-1}$ with loads of 15,30 , and 45 $\mathrm{N}$ for a constant sliding distance of $1.2 \mathrm{~km}$ using a computer interfaced pin-on-disc test rig according to ASTM: G 99-05 [19].

2.3.3. Morphological Study. A scanning electron microscope (SEM) (Model-JEOL-JSM-6380LA, Japan) was used to evaluate the texture and morphology of the carbon fabric, carbon fibers surface morphology before and after cryogenic treatment, as well as the worn-out composite specimens. In all the cases, the sample surfaces were sputtered with gold in a sputtering unit (Model: JEOL JFC 1600, Japan) autofine coater, to make them conductive. The images were taken at suitable accelerating voltages for the best possible resolution, using secondary electron imaging.

\section{Results and Discussion}

3.1. Morphology of Carbon Fabric and Cryogenic Treated and Untreated Carbon Fiber Surfaces. The SEM image of carbon fabric used as reinforcement for manufacturing laminates is shown in Figure 1(a). The image shows that it is of bidirectional, plain weave type and free from defect. The SEM images of fibers in the fabric as-received from the supplier shown in Figure 1(b) and after 4-minute cryogenic treatment are shown in Figure 1(c). Figures 1(b) and 1(c) show clearly visible variation in surface morphology of the cryogenically treated fibers and untreated fibers.

The surface structure difference observed through SEM is because of different coefficient of thermal expansion of carbon fiber core and amorphous carbon surface on the fiber at low temperature. This leads to removal of amorphous carbon from the surface. Dislodged amorphous carbon by this process accumulates nearby surface of the fiber and creates variation in size of the outer diameter and irregular geometry. This effect is proportional to the duration of treatment. But, in the literatures it is mentioned that the excess treatment deeply affects the surface of the fiber which reduces the size and the strength of fiber. As per the literature it was observed that 4minute duration is the optimum dwell time which gives remarkable surface roughness without much affecting the strength of the fiber. Hence, in the present study cryogenic treatment time of 4 minutes has been maintained. It is observed that there is no much variation in fiber diameter, but observed surface variations. The surface variation acts as mechanical interlocking with the epoxy matrix and increases the shear area of the fibers. The FESEM (field emission scanning electron microscope) image of MWCNTs dispersion 


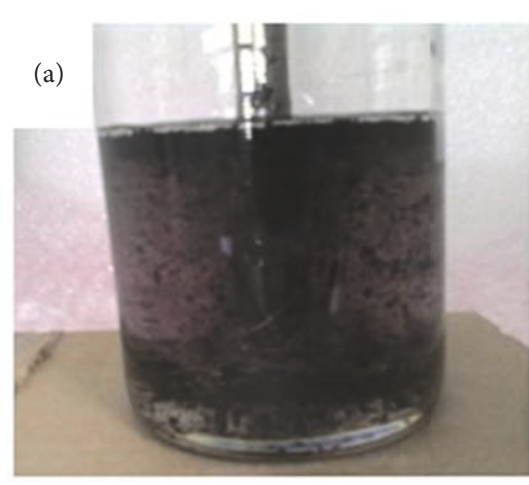

(a)

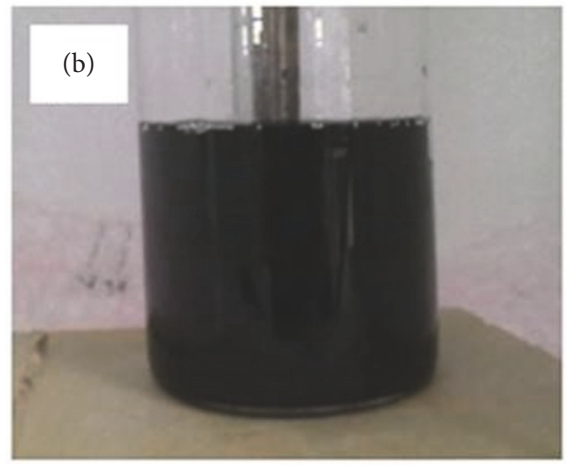

(b)

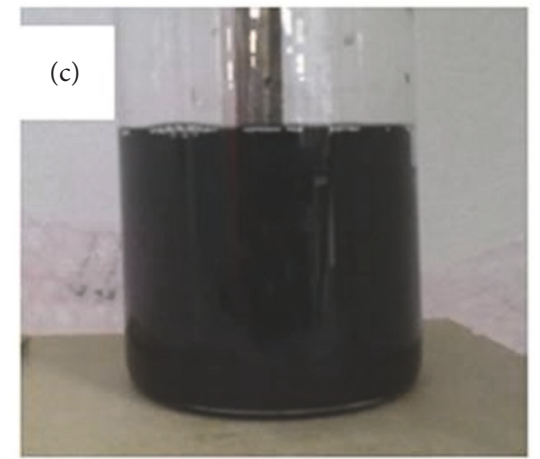

(c)

Figure 2: Status of Mix of MWCNT and epoxy resin after (a) 5 min; (b) 1 hour; (c) 2 hours of sonication.

in epoxy matrix is as shown in Figure 1(d). It is found that the MWCNTs uniformly dispersed in epoxy matrix. This is due to the synergetic effect of low volume percentage of surface treated MWCNTs and effectiveness of ultrasonication mixing.

3.2. Dispersion of MWCNT in Epoxy Matrix. The operating parameters of Sonics Vibra-Cell were set as mentioned in the Section 2.2.3. The resin containing MWCNTs was subjected to sonication. The dispersion status of MWCNTs in epoxy matrix at different time intervals is shown in Figures 2(a)2(c). It is observed that, after 2 hours of sonication, the MWCNTs uniformly dispersed and suspended in the epoxy matrix. This is due to bubbles which are formed in the epoxy matrix during sonication process by ultrasonic waves. The bubbles collapses, which results in high velocity jets and pressure gradients in the matrix system. In addition to this, the temperature of matrix increases and hence viscosity decreases. The above combined effect causes the separation of agglomerated MWCNTs which are weakly bonded by van der Waals forces and creates uniform distribution in the matrix. The morphology of dispersion of MWCNTs in cured epoxy matrix was examined through FESEM and found uniform dispersion (Figure 1(d)).

3.3. Mechanical Properties. Figure 3 shows the stress strain behavior and Table 1 shows the mechanical properties of $\mathrm{CF} / \mathrm{E}$ and $\mathrm{CCF} / \mathrm{O}-\mathrm{MWCNT} / \mathrm{E}$ composites. A slight change in tensile strength of CCF/O-MWCNT/E and CF/E composites has been observed. This small change may be due to variation in the samples. However, the MWCNTs in between carbon fibers, in carbon fabric layers, and in the fibers surface act as arresters for slippage and bridge the cracks and prevent crack propagation in the matrix. In addition to this the irregular surface of treated carbon fiber established a mechanical locking between carbon fiber and epoxy matrix. This enhances the matrix dominating properties like interlaminar shear strength and flexural strength of the composite.

Figure 4 shows the schematic of the reaction between chromic acid and MWCNTs. The MWCNTs treatment as explained in Section 2.2.2 helps in enhancing the matrix

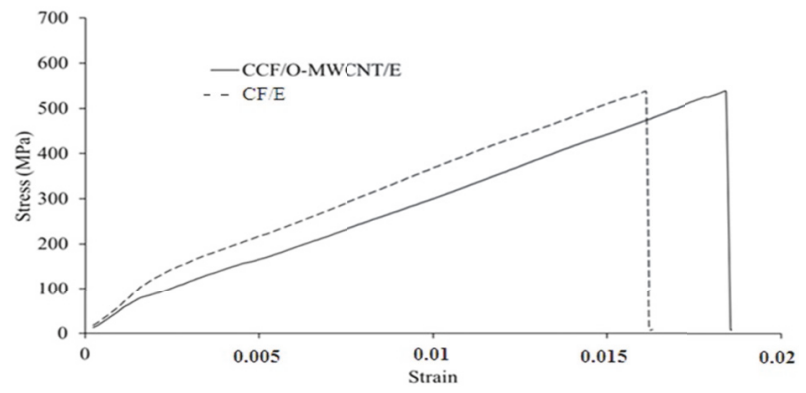

FIgURE 3: Stress strain behavior of CF/E and CCF/O-MWCNT/E composites.

dominating property. The MWCNTs are uniformly dispersed in the composite due to the sonication. This helps in reducing the stress concentration point by avoiding agglomeration of MWCNTs in the composite. Also, addition of oxygen atoms, $\mathrm{COOH}$, and $\mathrm{OH}$ groups of atom on the surface of the MWCNTs provides better chemical bonding with the epoxy matrix. This develops good interface between MWCNTs and matrix and helps in better load transfer from matrix to reinforcement. From the synergetic effect of the abovementioned mechanism, both fiber and matrix dominating properties are improved in the nanocomposite. Further it is also noticed that the specific gravity of the composite remains unchanged.

3.4. Specific Wear Rate. Figure 5 shows the specific wear rate of CF/E and CCF/O-MWCNT/E composites at loads of 15, 30 , and $45 \mathrm{~N}$ with sliding velocity of $1.5,2.5$, and $3 \mathrm{~m} . \mathrm{s}^{-1}$. The specific wear rate of CCF/O-MWCNT/E composites is lower in all the three loads and speeds compared to $\mathrm{CF} / \mathrm{E}$ composites. It is observed that initially a severe wear takes place in $\mathrm{CF} / \mathrm{E}$ composite at lower loads. This is because of brittle epoxy surface on the carbon fabric comes in contact with sliding metallic disc. Due to this surface of the composite undergoes brittle fracture and creates large debris which responsible for more wear of resin. As the load increases the fractured surface of matrix comes out from the sliding 
TABLE 1: Mechanical properties of CF/E and CCF/O-MWCNT/E composites.

\begin{tabular}{lcccccccc}
\hline Material code & $\begin{array}{c}\sigma_{\mathrm{t}} \\
(\mathbf{M P a})\end{array}$ & $\begin{array}{c}\mathrm{e} \\
(\mathbf{\%})\end{array}$ & $\begin{array}{c}\mathrm{E}_{\mathrm{t}} \\
(\mathbf{G P a})\end{array}$ & $\begin{array}{c}\sigma_{\mathrm{f}} \\
(\mathbf{M P a})\end{array}$ & $\begin{array}{c}\mathbf{E f} \\
(\mathbf{G P a})\end{array}$ & $\begin{array}{c}\boldsymbol{\tau}_{\text {ils }} \\
(\mathbf{M P a})\end{array}$ & $\begin{array}{c}\mathrm{VH} \\
(\mathbf{M P a})\end{array}$ & $\begin{array}{c}\rho \\
(\mathbf{g . c m}\end{array}$ \\
\hline $\mathrm{CF} / \mathrm{E}$ & 540 & 0.016 & 33.7 & 702 & 50.5 & 20 & 64 & 1.33 \\
\hline $\mathrm{CCF} / \mathrm{O}-\mathrm{WCNT} / \mathrm{E}$ & 558 & 0.018 & 31 & 827 & 51.8 & 25 & 72 \\
\hline
\end{tabular}

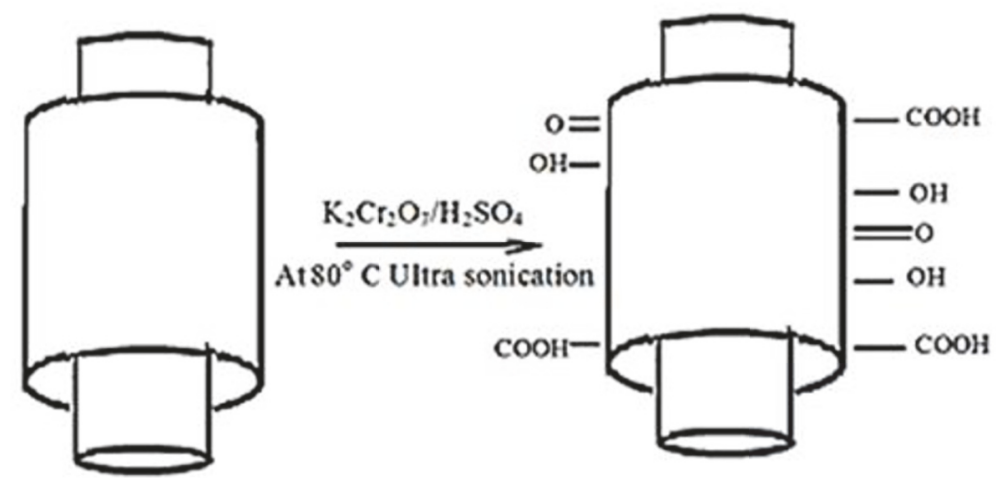

FIGURE 4: Schematic of the oxidation of MWCNTs by chromic acid.

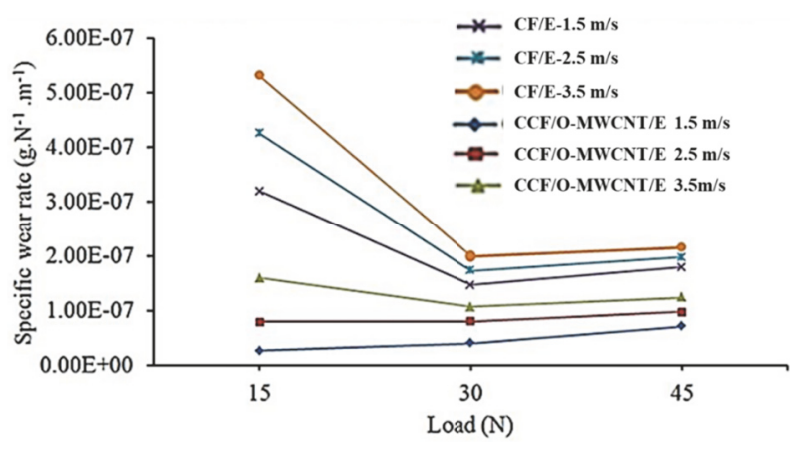

Figure 5: Specific wear rate of CF/E and CCF/O-MWCNT/E composites.

zone and some portion of carbon fabric comes in contact with the metal disc. Further, mild wear occurs due to selflubrication effect of carbon fiber. Hence, as the load increases the wear rate decreases in $\mathrm{CF} / \mathrm{E}$ composites. It is also found that the wear rate of $\mathrm{CF} / \mathrm{E}$ increases with increase in speed. As the speed increases the shear stress in the interfacial zone increases. Because of increase in shear stress the material removal due to shear also increases.

But the CCF/O-MWCNT/E composites behavior is different than $\mathrm{CF} / \mathrm{E}$ composite. The surface of epoxy matrix consists of MWCNTs enhanced the resistance to fracture. Also presence of MWCNTs in the matrix reduced the size of wear debris, MWCNTs dislodged from the surface mixed with small size epoxy wear debris, and creates uniform solid lubricant surface on the steel disc. This helps in reducing the wear further.

In case of CCF/O-MWCNT/E composites also the wear rate increased with speed due to increased shear stress at the interface zone. But, the solid lubricant present in between the sliding zone reduces this effect; hence, the amount of wear rate is less as compared to $\mathrm{CF} / \mathrm{E}$ composite. A stable wear rate is also observed as the load increases in CCF/O-MWCNT/E composites. However, speed is not much influential in both the composites at higher loads. This is because of reduced vibration and impact loads on the composites at higher loads.

3.5. Coefficient of Friction. Figures 6 and 7 show the friction behavior of CF/E and CCF/O-MWCNT/E composites subject to sliding action, respectively. The coefficient of friction increases in CCF/O-MWCNT/epoxy hybrid composites with increase in speed in almost all the cases consistently. The variation of friction coefficient with speed is due to presence of O-MWCNT in the composite which creates a stable film of MWCNTs wear debris in between counter surface. However, in case of $\mathrm{CF} / \mathrm{E}$ composites, the coefficient of friction is not consistent; it is independent of speed and load, which may be due to hard epoxy wear debris.

3.6. Morphology of Worn-Out Surfaces. SEM images of wornout surface of $\mathrm{CF} / \mathrm{E}$ composites and CCF/O-MWCNT/E composites at different loads and speeds are shown in Figures 8 and 9, respectively. In the SEM image of Figure 8(a), the surface damage is observed due to ploughing. This is because brittle fracture of surface matrix of $\mathrm{CF} / \mathrm{E}$ composite develops large size epoxy wear debris. Due to further sliding action, the large debris trapped in between sliding surfaces and crates ploughing. Similar effect was observed at higher speeds and lower load conditions (Figure 8(d)). Fiber pullout from the surface of the composite was observed in Figures $8(\mathrm{~b})$ and $8(\mathrm{i})$. This is because of poor interface between untreated carbon fabric and epoxy matrix. Surface delamination and subsurface cracks are developed due to poor interface between reinforcement and epoxy matrix as shown in the Figures 8(e), 8(f), and 8(h). 

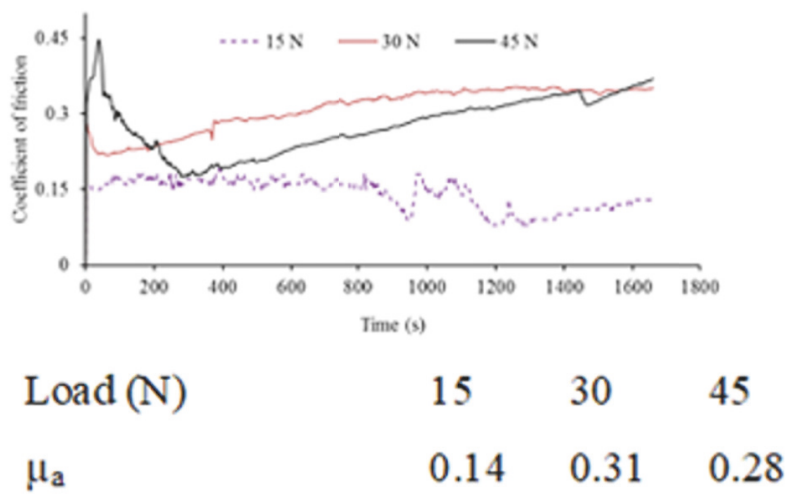

(a)
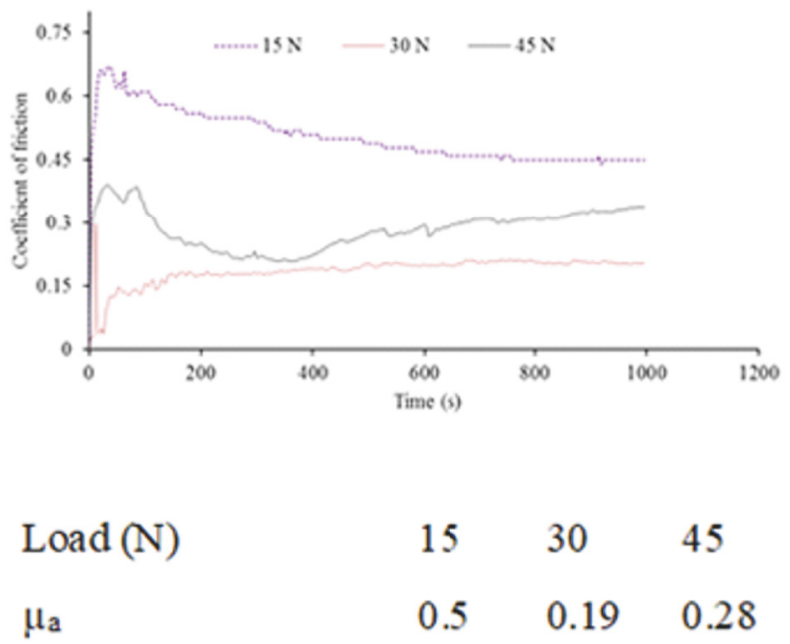

(b)
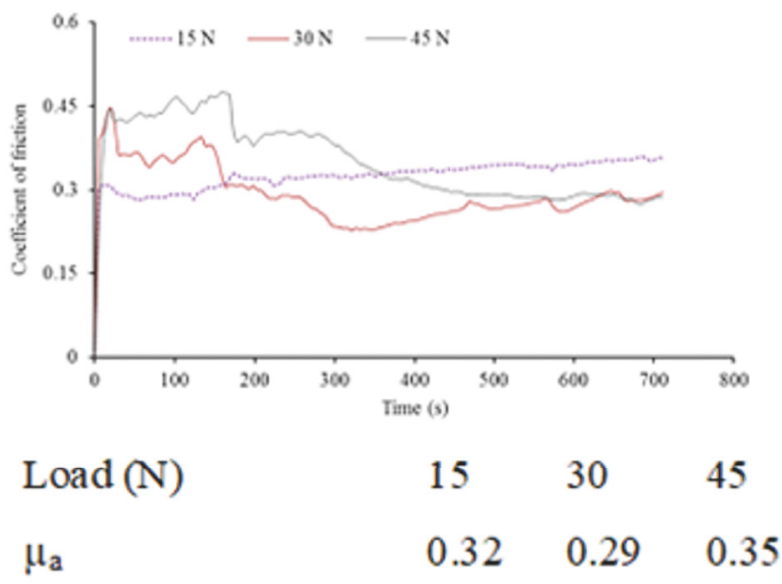

(c)

Figure 6: Coefficient of friction plots and average coefficient of friction of CF/E composites at sliding speed (a) $1.5 \mathrm{~m} . \mathrm{s}^{-1}$, (b) $2.5 \mathrm{~m} . \mathrm{s}^{-1}$, and (c) $3.5 \mathrm{~m} \cdot \mathrm{s}^{-1}$.

It is clear from the above microscopic observation that the $\mathrm{CF} / \mathrm{E}$ composite underwent severe matrix damage due to large wear debris which formed by brittle property of epoxy matrix. The low fracture toughness and brittleness of epoxy matrix lead to surface cracks and subsurface cracks and further sliding action results in delamination of matrix surface from the $\mathrm{CF} / \mathrm{E}$ composite.

From Figures 9(a) and 9(g), uniform wear is observed due to low friction which was developed due to presence of MWCNTs in the CCF/OMWCNT/E composite. Figure 9(d) 

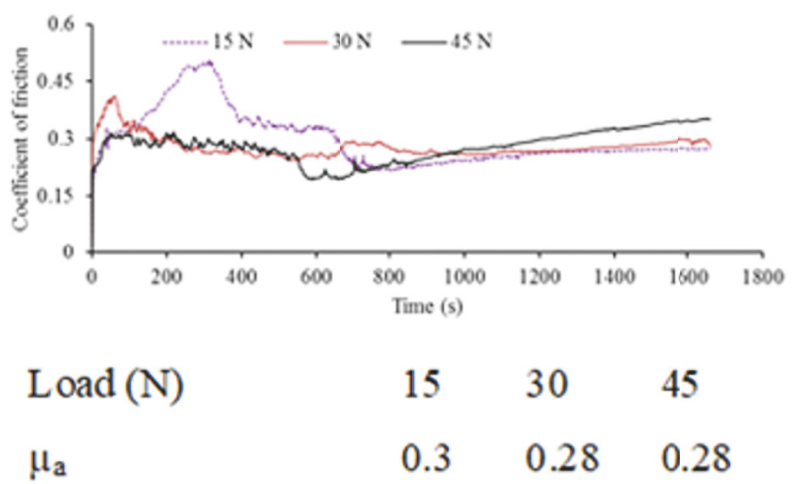

(a)
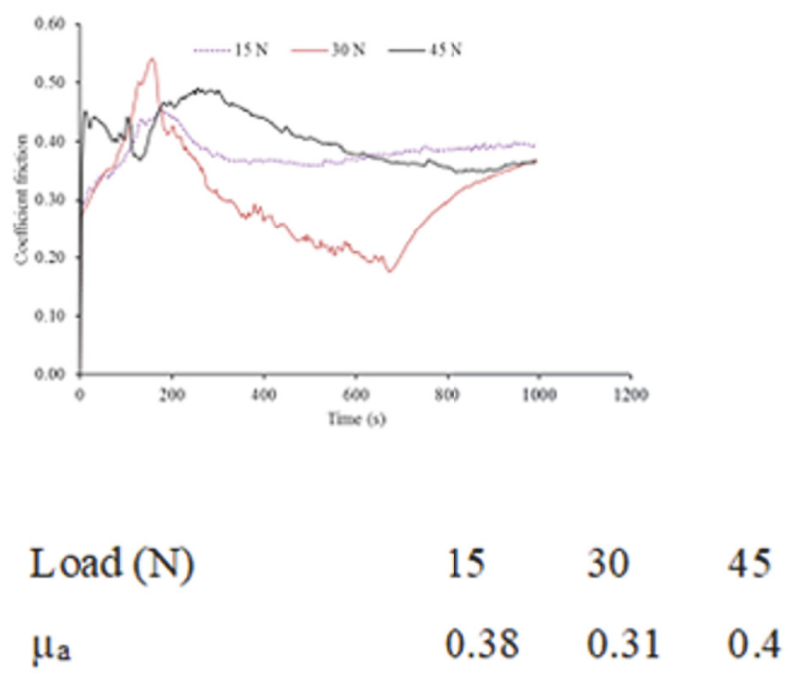

(b)

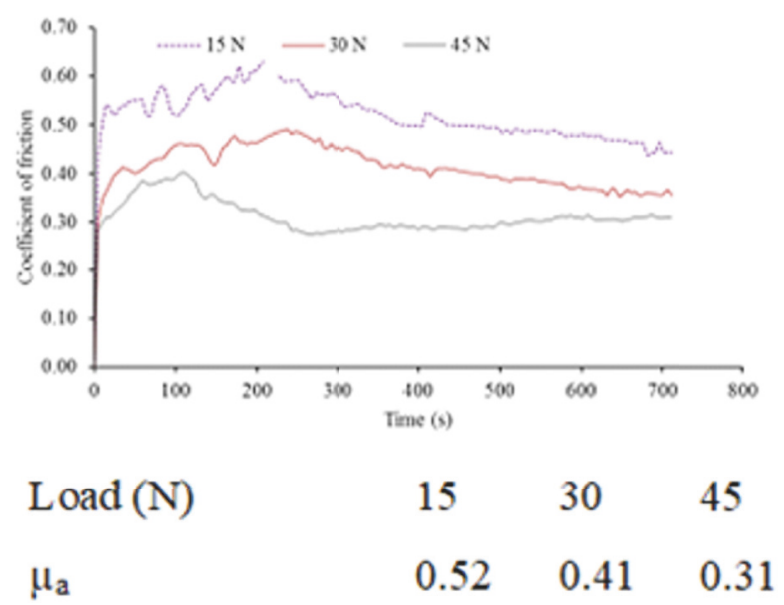

(c)

FIGURE 7: Coefficient of friction plots and average coefficient of friction of CCF/O-MWCNT/E composites at sliding speed (a) $1.5 \mathrm{~m} . \mathrm{s}^{-1}$, (b) $2.5 \mathrm{~m} \cdot \mathrm{s}^{-1}$, and (c) $3.5 \mathrm{~m} \cdot \mathrm{s}^{-1}$. 


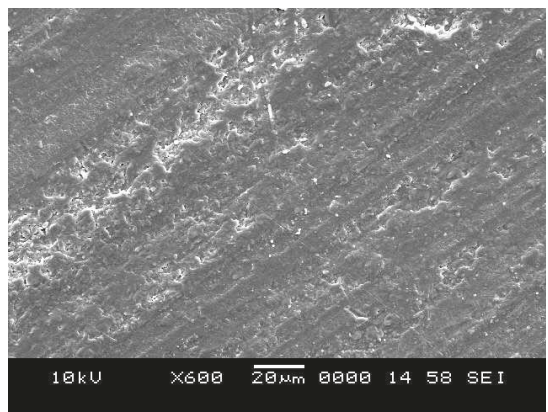

(a)

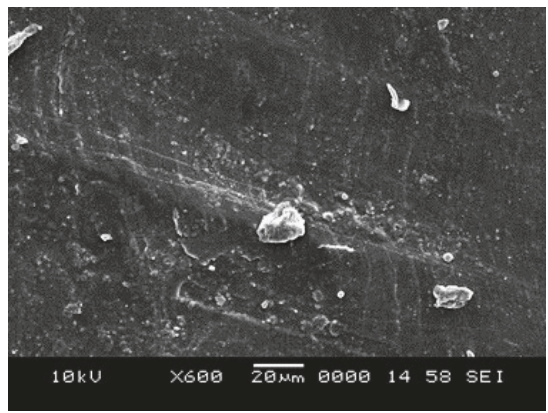

(d)

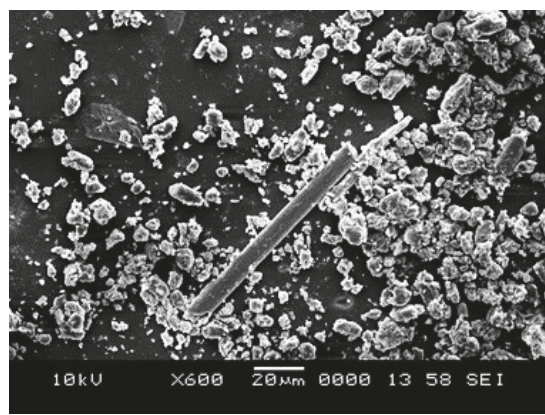

(g)

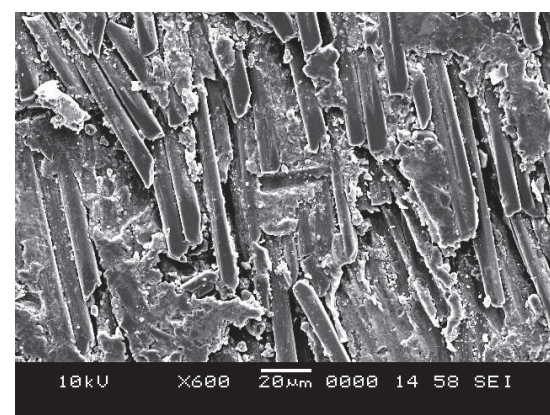

(b)

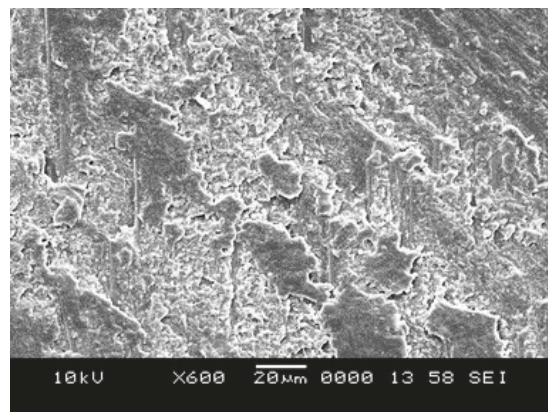

(e)

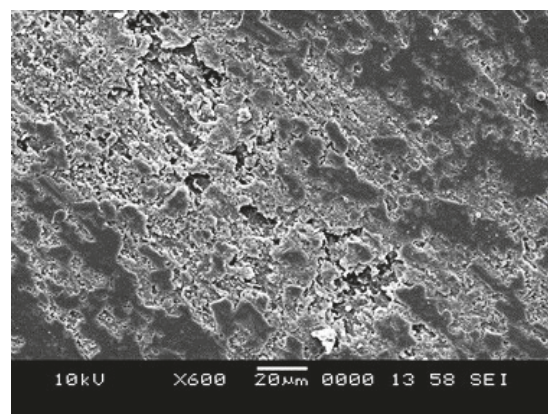

(h)

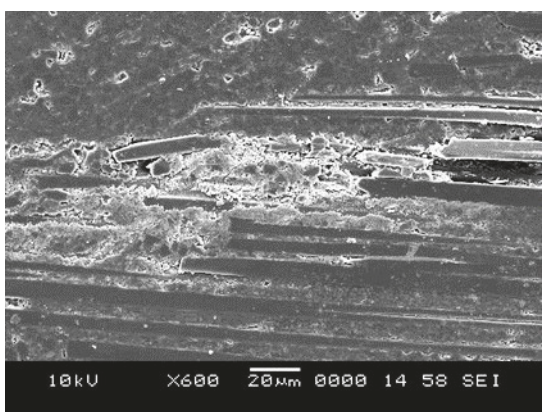

(c)

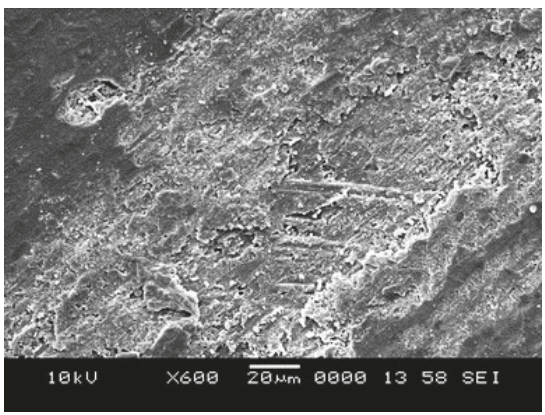

(f)

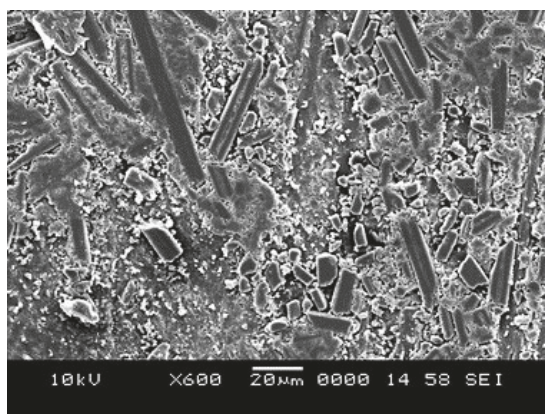

(i)

Figure 8: SEM images of worn-out surface of CF/E composites at different loads and speeds (a) $15 \mathrm{~N}, 1.5 \mathrm{~m}$. $\mathrm{s}^{-1}$ (b) $30 \mathrm{~N}, 1.5 \mathrm{~m}$. $\mathrm{s}^{-1}$ (c) $45 \mathrm{~N}$, $1.5 \mathrm{~m} . \mathrm{s}^{-1}$ (d) $15 \mathrm{~N}, 2.5 \mathrm{~m} . \mathrm{s}^{-1}$ (e) $30 \mathrm{~N}, 2.5 \mathrm{~m} . \mathrm{s}^{-1}$ (f) $45 \mathrm{~N}, 2.5 \mathrm{~m} . \mathrm{s}^{-1}$ (g) $15 \mathrm{~N}, 3.5 \mathrm{~m} . \mathrm{s}^{-1}$ (h) $30 \mathrm{~N}, 3.5 \mathrm{~m} . \mathrm{s}^{-1}$, and (i) $45 \mathrm{~N}, 3.5 \mathrm{~m} . \mathrm{s}^{-1}$.

shows mild ploughing of surface due to small size wear debris. Further sliding creates plastic deformation of matrix and material removed in the form of fine size debris. This indicates that the material removal rate in case of $\mathrm{CCF} / \mathrm{O}$ MWCNT/E composite is mild compared to CF/E composite. Also, it is observed that the fiber fracture and matrix fracture at higher loads in all the speeds of CCF/O-MWCNT/E composites. But, the fibers pull-out and fiber damage is not much frequent compared to $\mathrm{CF} / \mathrm{E}$ composite. From this, it is noticed that a better interface between reinforcements (MWCNTs and carbon fiber) and matrix has been achieved due to treatment of fiber and filler. Thus the better interface leads to structural integrity improvement. The presence of
MWCNTs in the composite matrix improves the toughness, acts as solid lubricant, and reduces the wear.

\section{Conclusions}

The cryogenically treated carbon fabric-reinforced MWCNTs filled epoxy composite shows relatively good mechanical properties and sliding wear resistance as compared to untreated carbon fiber reinforced untreated epoxy composite. The cryogenic treatment of carbon fabric develops uneven surface structure and hence it helps in improving matrix dominating properties. Addition of MWCNTs to epoxy matrix improved the toughness and acts as solid lubricant 


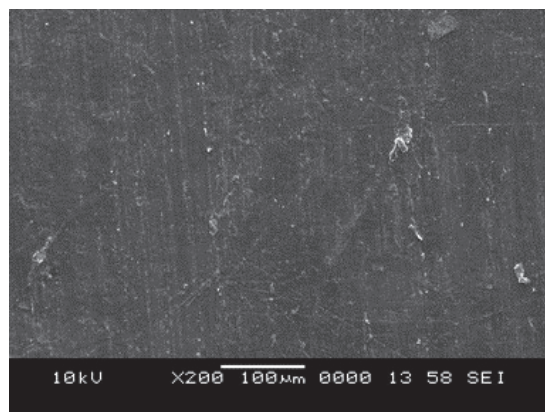

(a)

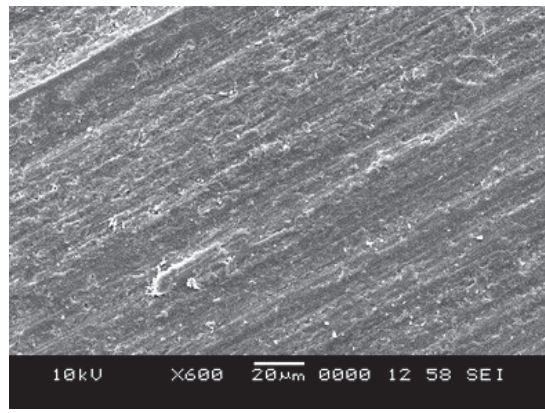

(d)

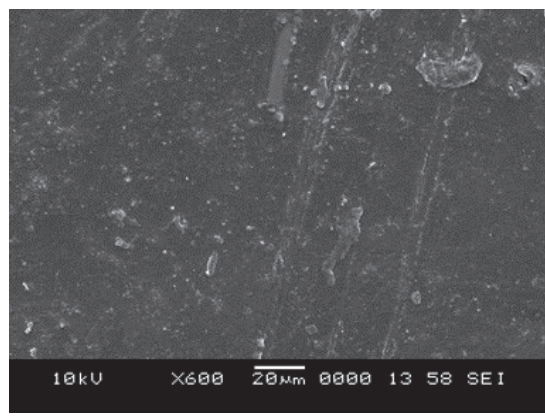

(g)

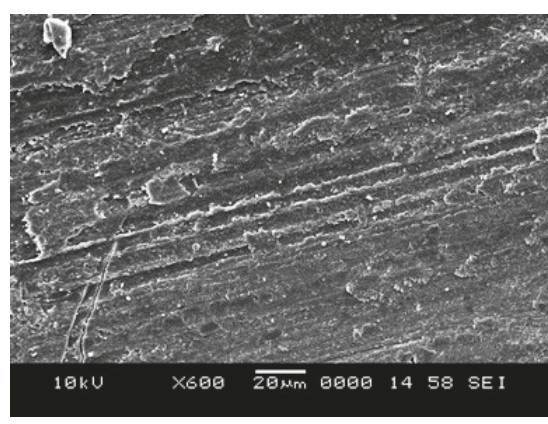

(b)

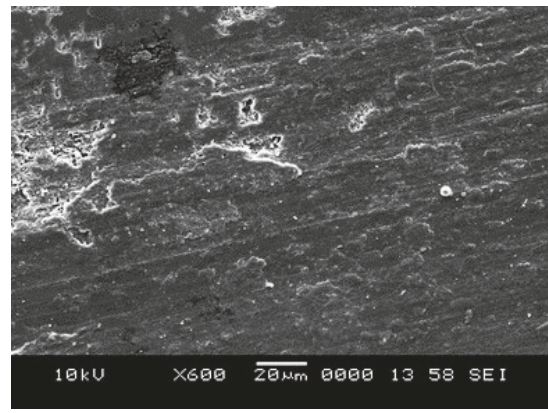

(e)

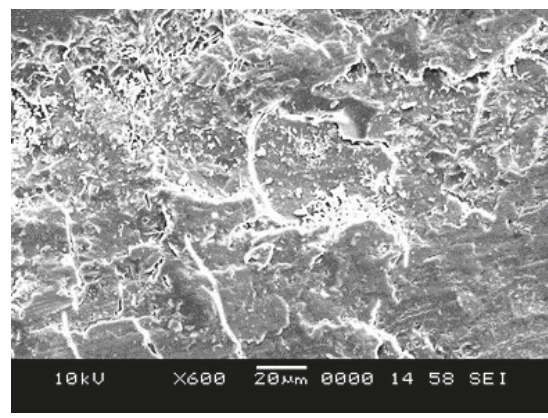

(h)

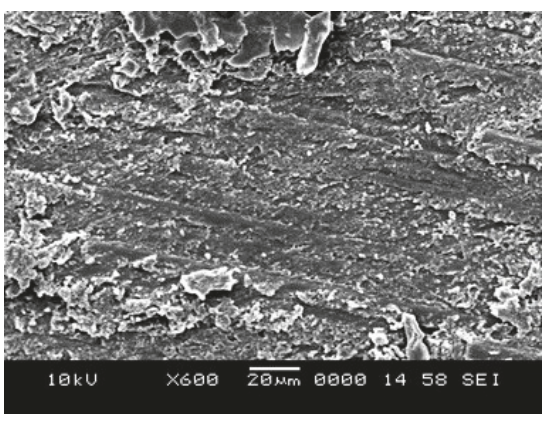

(c)

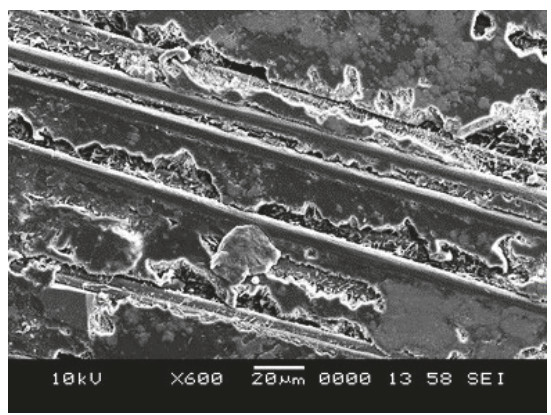

(f)

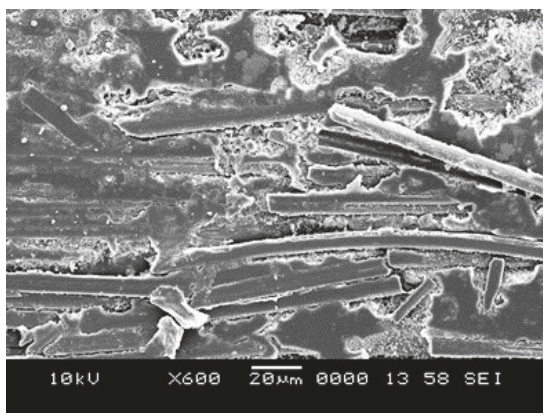

(i)

FIGURE 9: SEM images of worn-out surface of CCF/O-MWCNT/E composites at different loads and speeds (a) $15 \mathrm{~N}, 1.5 \mathrm{~m}$. $\mathrm{s}^{-1}$ (b) $30 \mathrm{~N}, 1.5$

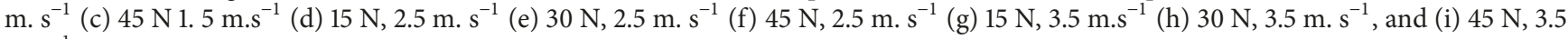
m. $\mathrm{s}^{-1}$.

during sliding. The film established by MWCNTs in sliding reduces the friction and wear. The CCF/O-MWCNT/E composite exhibits better properties as compared to $\mathrm{CF} / \mathrm{E}$ composite.

\section{Data Availability}

The data used to support the findings of this study are available from the corresponding author upon request.

\section{Conflicts of Interest}

The authors declare that they have no conflicts of interest.

\section{References}

[1] J. M. F. De Paiva, A. De Nadai Dos Santos, and M. C. Rezende, "Mechanical and morphological characterizations of carbon fiber fabric reinforced epoxy composites used in aeronautical field," Materials Research, vol. 12, no. 3, pp. 367-374, 2009.

[2] I. M. Daniel and O. Ishai, Engineering mechanics of composite materials, 2nded, Oxford University Press Inc, New York, NY, USA, 2006.

[3] H. Dhieb, J. Buijnsters, F. Eddoumy, and J. Celis, "Surface damage of unidirectional carbon fiber reinforced epoxy composites under reciprocating sliding in ambient air," Composites Science and Technology, vol. 71, no. 15, pp. 1769-1776, 2011.

[4] K. Kumaresan, G. Chandramohan, M. Senthilkumar, B. Suresha, and S. Indran, "Dry sliding wear behaviour of carbon fabric-reinforced epoxy composite with and without silicon carbide," Composite Interfaces, vol. 18, no. 6, pp. 509-526, 2011.

[5] J. Cho, J. Y. Chen, and I. M. Daniel, "Mechanical enhancement of carbon fiber/epoxy composites by graphite nanoplatelet reinforcement," Scripta Materialia, vol. 56, no. 8, pp. 685-688, 2007. 
[6] Q. B. Guo, M. Z. Rong, G. L. Jia, K. T. Lau, and M. Q. Zhang, "Sliding wear performance of nano-SiO2/short carbon fiber/ epoxy hybrid composites," Wear, vol. 266, no. 7-8, pp. 658-665, 2009.

[7] F. H. Gojny, J. Nastalczyk, Z. Roslaniec, and K. Schulte, "Surface modified multi-walled carbon nanotubes in CNT/epoxy-composites," Chemical Physics Letters, vol. 370, no. 5-6, pp. 820-824, 2003.

[8] Y. Breton, S. Delpaux, R. Benoit, J. P. Salvetat, C. Sinturel, and F. Beguin, "Functionalization of multi walled carbon nano tubes: properties of nano tubes-epoxy composites," Mol. Cryst. Liq. Cryst, vol. 387, p. p135, 2002.

[9] A. M. Shanmugharaj, J. H. Bae, K. Y. Lee, W. H. Noh, S. H. Lee, and S. H. Ryu, "Physical and chemical characteristics of multiwalled carbon nanotubes functionalized with aminosilane and its influence on the properties of natural rubber composites," Composites Science and Technology, vol. 67, no. 9, pp. 1813-1822, 2007.

[10] L. Chang and K. Friedrich, "Enhancement effect of nanoparticles on the sliding wear of short fiber-reinforced polymer composites: A critical discussion of wear mechanisms," Tribology International, vol. 43, no. 12, pp. 2355-2364, 2010.

[11] F. Su, Z. Zhang, K. Wang, W. Jiang, X. Men, and W. Liu, "Friction and wear properties of carbon fabric composites filled with nano-Al2O3 and nano-Si3N4," Composites Part A: Applied Science and Manufacturing, vol. 37, no. 9, pp. 1351-1357, 2006.

[12] B. Suresha, Siddaramaiah, Kishore, S. Seetharamu, and P. S. Kumaran, "Investigations on the influence of graphite filler on dry sliding wear and abrasive wear behaviour of carbon fabric reinforced epoxy composites," Wear, vol. 267, no. 9-10, pp. 14051414, 2009.

[13] X. H. Zhou, Y. S. Sun, and W. S. Wang, "Influences of carbon fabric/epoxy composites fabrication process on its friction and wear properties," Journal of Materials Processing Technology, vol. 209, no. 9, pp. 4553-4557, 2009.

[14] J. Zhu, J. Kim, H. Peng, J. L. Margrave, V. N. Khabashesku, and E. V. Barrera, "Improving the dispersion and integration of single-walled carbon nanotubes in epoxy composites through functionalization," Nano Letters, vol. 3, no. 8, pp.1107-1113, 2003.

[15] D. ASTM, "Standard test method for density and specific gravity (relative density) of plastics by displacement," Pennsylvania, USA, 2012.

[16] D. ASTM, "Standard test method for tensile properties of plastics," Pennsylvania, USA, 2012.

[17] D. ASTM, "Standard test method for flexural properties of unreinforced and reinforced plastics and electrical insulating materials," Pennsylvania, USA, 2012.

[18] D. ASTM, "Standard test method for apparent interlaminar shear strength of parallel fiber composite by short beam method," Pennsylvania, USA, 2012.

[19] G. ASTM, "Standard test method for wear testing with pin-ondisc apparatus," Pennsylvania, USA, 2012. 


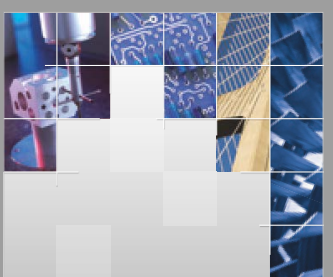

\section{Enfincering}
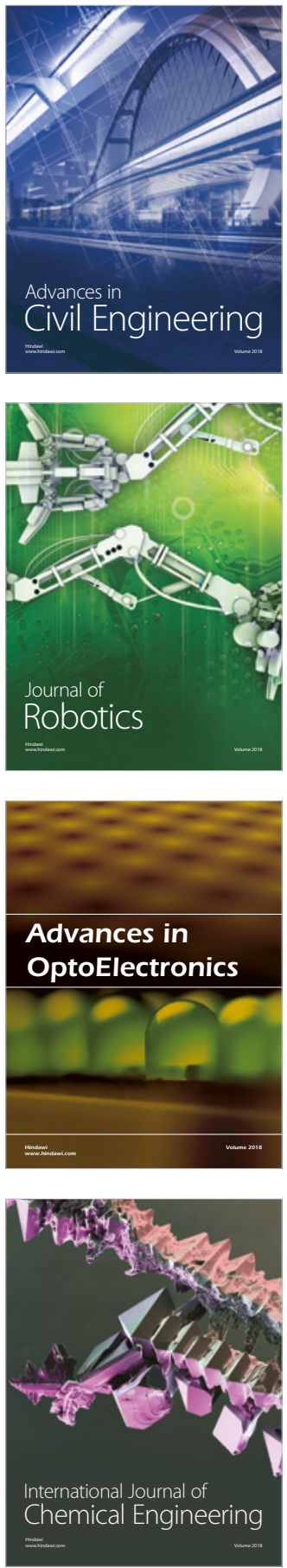

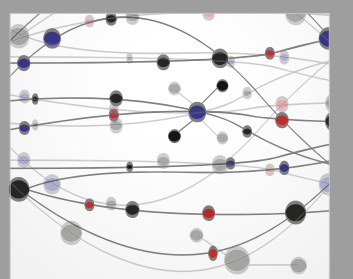

\section{Rotating \\ Machinery}

The Scientific World Journal

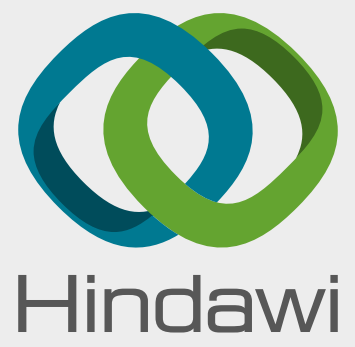

Submit your manuscripts at

www.hindawi.com
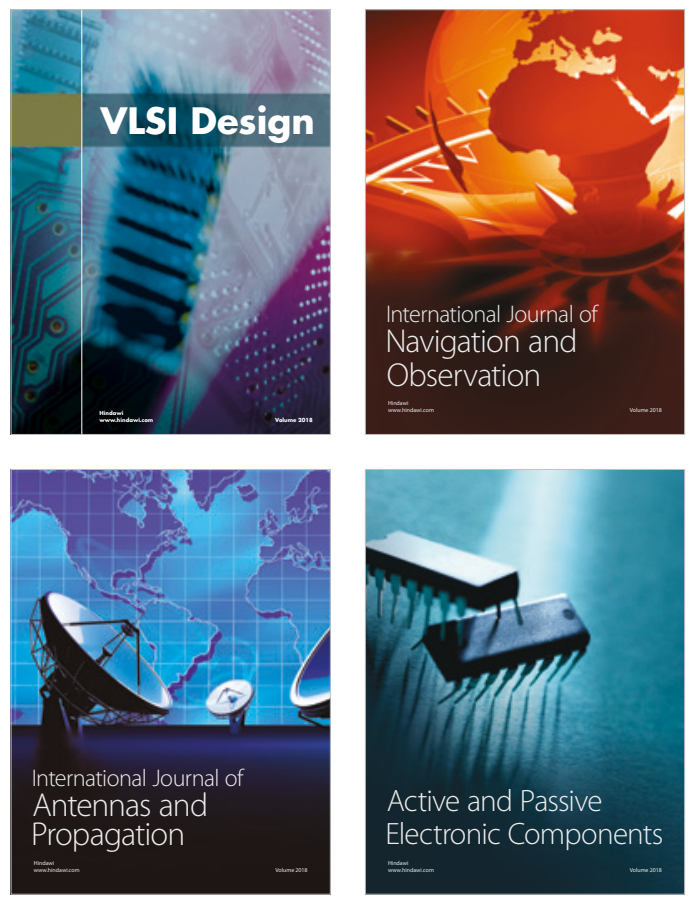
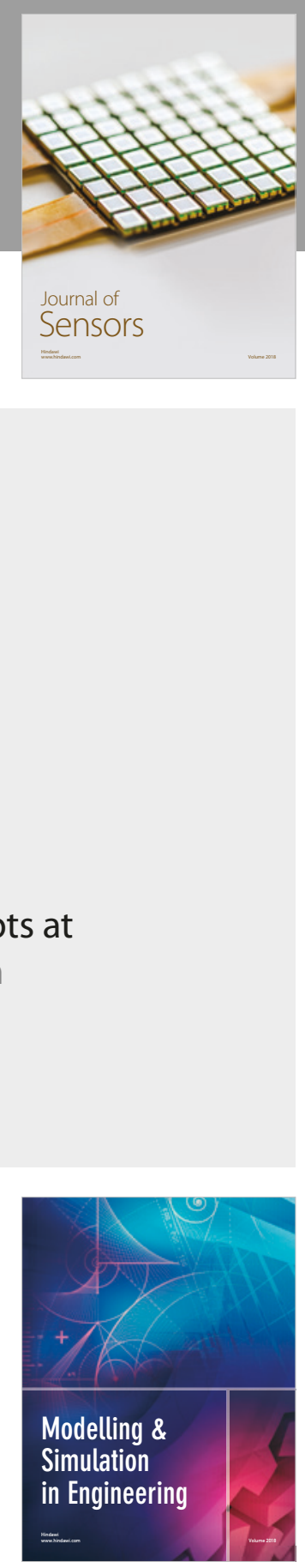

\section{Advances \\ Multimedia}
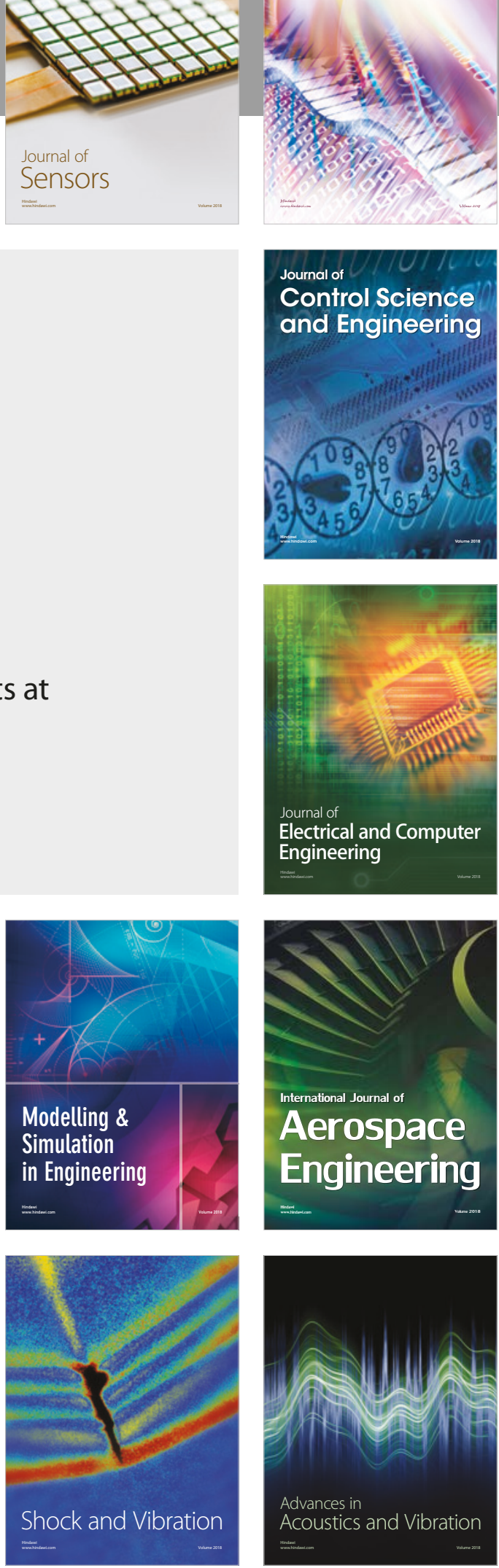